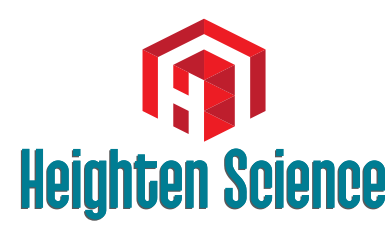

P U B L I C A T I O N S Corporation

\title{
A decade of targeted therapy for non-small cell lung cancer
}

\author{
Khalid Abu Ajaj* \\ CytRx Corporation, Drug Discovery Branch, Engesserstr. 4, D-79108 Freiburg, Germany
}

*Address for Correspondence: Khalid Abu Ajaj, CytRx Corporation, Drug Discovery Branch, Engesserstr. 4, D-79108 Freiburg, Germany, Email: khalid@abuajaj.com

Submitted: 22 September 2017

Approved: 27 September 2017

Published: 28 September 2017

Copyright: @ 2017 Abu Ajaj K. This is an open access article distributed under the Creative Commons Attribution License, which permits unrestricted use, distribution, and reproduction in any medium, provided the original work is properly cited

\section{Abstract}

Chemotherapy is one of the main treatment options for cancer. However, chemotherapeutic agents usually suffer from poor pharmaceutical properties that restrict their use. Targeted therapy drugs have been developed to specifically target changes in cancer cells that help these cells to grow. Such drugs often work when standard chemotherapeutic drugs do not, they often have less severe side effects and they are most often used for advanced cancers. The objective of this article is to give an overview about the 16 FDA-approved targeted therapy drugs to treat non-small cell lung cancer.

Non-small cell lung cancer (NSCLC) is the most common type of lung cancer. Subtypes of NSCLC include squamous cell carcinoma, adenocarcinoma, large cell carcinoma and the less common adenosquamos carcinoma and sarcomatoid carcinoma.

Many factors increase the risk for NSCLC such as smoking, genetic factors, exposure to radon gas, asbestos, second-hand smoke, or other forms of air pollution.

Signs or symptoms are usually not observed in the early stages of lung cancer, but many signs of eventually developed NSCLC include persistent cough, coughing up blood, persistent breathlessness, unexplained tiredness and weight loss, and an ache or pain when breathing or coughing.

Diagnosis of NSCLC can be achieved with different methods such as chest radiographs and computed tomography (CT) scans, which can be confirmed by biopsy that is usually performed by bronchoscopy or CT-guidance.

Treatment options of NSCLC include surgical tumor removal, radiation therapy, radiofrequency ablation, immunotherapy and chemotherapy. There are a number of factors that determine which methods achieve the best therapeutic outcome. Small tumors are often treated successfully with surgical removal alone because they do not have the potential to metastasize. Malignant tumors, however, are most often treated with a combination therapy. In some cases, non-curative surgery may make other treatments more effective. Chemotherapeutic agents usually suffer from poor pharmaceutical properties such as poor water-solubility or stability, and chemotherapy is accompanied with systemic toxicities. Furthermore, sufficient concentrations of the anticancer drug are often not achieved in tumor cells because of the lack of accumulation of the drugs in solid tumors.

Targeted therapy drugs have been developed to specifically target changes in NSCLC cells that help these cells to grow [1]. Such drugs work differently from the standard chemotherapy, they sometimes work when chemotherapeutic drugs do not, they often have less severe side effects and they are most often used for advanced lung cancers, either as a single therapy or in combination with chemotherapeutic drugs. 
Currently, and 11 years after the approval of the first targeted therapy drug Avastin in 2006 [2], 16 FDA-approved targeted therapy drugs are being used to treat NSCLC, three of them (Alunbrig [3], Tafinlar and Mekinist [4]) got their first approvals in 2017 [4]. According to their route of administration, they can be classified as orally or intravenously drugs. According to their mode of action, they can be classified into 4 categories: angiogenesis inhibitors [5], human EGFR inhibitors [6], tyrosine kinase inhibitors and PD-1 inhibitors [7].

Two drugs are being used to treat NSCLC with VEGF and taken as an infusion into a vein (IV). These angiogenesis inhibitors target and block the tumor blood vessel growth (angiogenesis) i.e. target the vascular endothelial growth factor (VEGF) [8], a protein that helps new blood vessels to form. Bevacizumab (Avastin, Roche) [9] (Avastin, Roche) was approved in 2006 as a first-line treatment of patients with locally advanced, metastatic or recurrent NCCLC in combination with platinum-based chemotherapy [2]. Ramucirumab (Cyramza, Eli Lilly and Company) [10] (Cyramza, Eli Lilly and Company) was approved in 2014 in combination with docetaxel for the treatment of patients with metastatic NSCLC with disease progression on or after platinum-based chemotherapy [11].

One drug is being used to treat NSCLC with EGFR and taken as an infusion into a vein (IV). This human EGFR inhibitor targets and blocks the signal from the epidermal growth factor receptor (EGFR), a protein on the surface of cells that due to its overexpression in some NSCLC helps these cells to grow faster and divide [12]. Necitumumab [13] (Portrazza, Eli Lilly and Company) was approved in 2015 in combination with gemcitabine and cisplatin for first-line treatment of patients with metastatic squamous NSCLC [14].

Three drugs are being used to treat NSCLC with PD-1 and taken as an infusion into a vein (IV). These PD-1 inhibitors block PD-1, programmed cell death protein 1, and thus activate the immune system to attack tumors [7]. Pembrolizumab (Keytruda, Merck and Co., Inc.) [15] was approved in 2015 for the treatment of patients with metastatic NSCLC whose tumors express programmed death ligand 1 (PD-L1) with disease progression on or after platinum-containing chemotherapy [16]. It was further approved in 2016 for the treatment of patients with metastatic NSCLC whose tumors express PD-L1 [17], and approved in 2017 in combination with pemetrexed and carboplatin for the treatment of patients with previously untreated metastatic NSCLC [4]. Atezolizumab (Tecentriq, Genentech Oncology) [18] was approved in 2016 for the treatment of patients with metastatic NSCLC whose disease progressed during or following platinum-containing chemotherapy. Patients with EGFR or ALK genomic tumor aberrations should have disease progression prior to receiving atezolizumab [19]. Nivolumab (Opdivo, Bristol-Myers Squibb Co.) [20] was approved in 2015 for the treatment of patients with metastatic squamous NSCLC with progression on or after platinum-based chemotherapy. It was also approved in 2015 for the treatment of patients with metastatic NSCLC with progression on or after platinum-based chemotherapy. Patients with EGFR or ALK genomic tumor aberrations should have disease progression prior to receiving Opdivo [21]. In 2016 FDA modified its dosage regimen for NSCLC [4].

Tyrosine kinase inhibitors include drugs that target cells with EGFR gene mutations [12], cells with T790M mutation [22], cells with ALK gene changes [23] or cells with BRAF gene changes [24]. Ten tyrosine kinase inhibitors are approved to treat NSCLC.

Three drugs are being used to treat NSCLC with EGFR gene mutations and taken as pills. These drugs are used alone as the first treatment for advanced NSCLCs that have certain mutations in the EGFR gene, which are more common in women and people who have not smoked [25]. Erlotinib (Tarceva, Astellas Pharma Inc.) [26,27] was approved in 2010 for maintenance treatment of patients with locally advanced 
or metastatic NSCLC whose disease has not progressed after four cycles of platinumbased first-line chemotherapy. It was further approved in 2013 for first-line treatment of metastatic NSCLC patients whose tumors have EGFR exon 19 deletions or exon 21 (L858R) substitution mutations [28]. In 2016 FDA modified its indication for treatment of NSCLC to limit use to patients whose tumors have specific EGFR mutations [4]. Afatinib (Gilotrif, Boehringer Ingelheim Pharmaceuticals, Inc.) was approved in 2013 for first-line treatment of patients with metastatic NSCLC whose tumors have EGFR exon 19 deletions or exon 21 (L858R) substitution mutations. Gefitinib (Iressa, AstraZeneca) was approved in 2015 for the treatment of patients with metastatic NSCLC whose tumors have EGFR exon 19 deletions or exon 21 (L858R) substitution mutations.

One drug is being used to treat NSCLC with T790M mutation and taken as tablet. EGFR inhibitors stop working during the treatment for most people, usually because the cancer cells develop another mutation in the EGFR gene such as the T790M mutation [22]. Osimertinib (Tagrisso, 2015, AstraZeneca Pharmaceuticals, LP) [33,34], an EGFR inhibitor that works against cells with the T790M mutation, was approved in 2015 for the treatment of patients with EGFR T790M mutation-positive NSCLC, who have progressed on or after EGFR tyrosine kinase inhibitor therapy. It was further approved in 2017 for the treatment of patients with metastatic EGFR T790M mutation-positive NSCLC, whose disease has progressed on or after EGFR tyrosine kinase inhibitor therapy [4].

Four drugs are being used to treat NSCLC with ALK gene changes and taken as pills. Some NSCLCs have a rearrangement in a gene called anaplastic lymphoma kinase (ALK), a change is most often seen in non-smokers (or light smokers) who have the adenocarcinoma subtype of NSCLC. The ALK gene rearrangement produces an abnormal ALK protein that causes the cells to grow and spread [23]. Drugs that target the abnormal ALK protein can often shrink tumors in people whose lung cancers have the ALK gene change. Although they can help after chemo has stopped working, they are often used instead of chemo in people whose cancers have the ALK gene rearrangement. Some of these drugs are useful in treating people whose cancers have changes in the ROS1 gene. Crizotinib (Tagrisso, AstraZeneca Pharmaceuticals, LP) $[35,36]$ was approved in 2015 for the treatment of patients with locally advanced or metastatic NSCLC that is ALK-positive. It was further approved in 2013 for the treatment of patients with metastatic NSCLC whose tumors are ALK-positive [4] and approved in 2016 for the treatment of patients with metastatic NSCLC whose tumors are ROS1-positive [37]. Ceritinib (Zykadia, Novartis Pharmaceuticals Corporation) [38,39] was approved in 2014 for the treatment of patients with ALK-positive, metastatic NSCLC with disease progression on or who are intolerant to crizotinib, and approved in 2017 for patients with metastatic NSCLC whose tumors are ALK-positive [4]. Alectinib (Alecensa, Hoffmann-La Roche Inc.) [40,41] was approved in 2015 for the treatment of patients with ALK-positive metastatic NSCLC who have progressed on or are intolerant to crizotinib. Brigatinib (Alunbrig, ARIAD Pharmaceuticals, Inc.) [3,42] was approved in 2017 for the treatment of patients with metastatic ALK-positive NSCLC who have progressed on or are intolerant to crizotinib.

Two drugs are being used to treat NSCLC with BRAF gene changes and taken as pills. Some NSCLCs have changes in the BRAF gene, a human gene that encodes a protein called B-Raf that helps them to grow [24]. Two drugs that target this protein and related proteins are used to treat metastatic NSCLC if it has a certain type of BRAF gene change. Dabrafenib (Tafinlar, Novartis Pharmaceuticals Inc.) [43], is a type of drug known as a BRAF inhibitor, which attacks the BRAF protein directly. Trametinib (Mekinist, Novartis Pharmaceuticals Inc.) [44], is known as a MEK inhibitor, because it attacks the related MEK proteins. A combination of both drugs was approved in 2017 for patients with metastatic NSCLC with BRAF V600E mutation [4]. 


\section{In summary}

With 11 years old is the targeted therapy of lung cancer still young but promising with 16 FDA-approved drugs to treat NSCLC. The targeted therapy drugs have been developed to specifically target changes in the cancer cells, a process that improves the antitumor efficacy and reduces the systemic toxicity over the traditional chemotherapy. Such drugs have proven to be successful in treating lung cancer either in a single therapy or in combination with other drugs. Oral administration of many drugs is an additional advantage of this therapy. Last but not least, personalized drugs that address protease expression and gene mutations in tumor patients forms a strong logic for a drug candidate to obtain a market approval.

\section{References}

1. Dolly So, Collins DC, Sundar R, Popat S, Yap TA. Advances in the Development of Molecularly Targeted Agents in Non-Small-Cell Lung Cancer. Drugs. 2017; 77: 813-827. Ref.: https://goo.gl/XjqRJw

2. No Authors. FDA approves Avastin in combination with chemotherapy for first-line treatment of most common type of lung cancer. Cancer Biol Ther. 2006; 5: 1425-1428. Ref.: https://goo.gl/wRvL5W

3. Markham A. Brigatinib: First Global Approval. Drugs. 2017; 77: 1131-1135. Ref.: https://goo.gl/bEYp8G

4. www.fda.gov.

5. Horn L, Sandler A. Chemotherapy and antiangiogenic agents in non-small-cell lung cancer. Clin Lung Cancer. 2007; 8: 68-73. Ref.: https://goo.gl/bbKEXJ

6. Hennequin C. Targeted therapies and radiotherapy in lung cancer. Cancer Radiother. 2007; 11: 7783. Ref.: https://goo.gl/KFgHJm

7. Sunshine J, Taube JM. PD-1/PD-L1 inhibitors. Curr Opin Pharmacol. 2015; 23: 32-38. Ref.: https://goo.gl/fr4u92

8. Cardones AR, Banez LL. VEGF inhibitors in cancer therapy. Curr Pharm Des. 2006; 12: 387-394. Ref.: https://goo.gl/auKpiw

9. Shih T, Lindley C. Bevacizumab: an angiogenesis inhibitor for the treatment of solid malignancies. Clin Ther. 2006; 28: 1779-1802. Ref.: https://goo.gl/dgq4Ud

10. Aprile G, Rijavec E, Fontanella C, Rihawi K, Grossi F. Ramucirumab: preclinical research and clinical development. Onco Targets Ther. 2014; 7: 1997-2006. Ref.: https://goo.gl/VGbGe5

11. Fala L. Cyramza (Ramucirumab) Approved for the Treatment of Advanced Gastric Cancer and Metastatic Non-Small-Cell Lung Cancer. Am Health Drug Benefits. 2015; 8; 49-53. Ref.: https://goo.gl/m7YmSt

12. Metro G, Finocchiaro G, Toschi L, Elisabetta M, Alessandra $C$, et al. Epidermal growth factor receptor (EGFR) targeted therapies in non-small cell lung cancer (NSCLC). Rev Recent Clin Trials. 2006; 1 : 1-13. Ref.: https://goo.gl/x25PLq

13. Pillai RN, Ramalingam SS. Necitumumab: a new therapeutic option for squamous cell lung cancer? Transl Lung Cancer Res. 2014; 3: 382-383. Ref.: https://goo.gl/nCpDgg

14. Fala L. Portrazza (Necitumumab), an IgG1 Monoclonal Antibody, FDA Approved for Advanced Squamous Non-Small-Cell Lung Cancer. Am Health Drug Benefits. 2016; 9; 119-122. Ref.: https://goo.gl/gGFrbV

15. McDermott J, Jimeno A. Pembrolizumab: PD-1 inhibition as a therapeutic strategy in cancer. Drugs Today (Barc). 2015; 51: 7-20. Ref.: https://goo.gl/eJCaXN

16. Lim SH, Sun JM, Lee SH, Ahn JS, Park K, et al. Pembrolizumab for the treatment of non-small cell lung cancer. Expert Opin Biol Ther. 2016; 16: 397-406. Ref.: https://goo.gl/TPPqxn

17. Pai-Scherf L, Blumenthal GM, Li H, Subramaniam S, He K, et al. FDA Approval Summary: Pembrolizumab for Treatment of Metastatic Non-Small Cell Lung Cancer: First-Line Therapy and Beyond. Oncologist. 2017. Ref.: https://goo.gl/56EANN

18. Krishnamurthy A, Jimeno A. Atezolizumab: A novel PD-L1 inhibitor in cancer therapy with a focus in bladder and non-small cell lung cancers. Drugs Today (Barc). 2017; 53: 217-237. Ref.: https://goo.gl/vfSHk4 
19. Markham A. Atezolizumab: First Global Approval. Drugs. 2016; 76: 1227-1232. Ref.: https://goo.gl/uUc3un

20. Flippot R, Fallet V, Besse B, Wislez M, Vignot $\mathrm{S}$, et al. Nivolumab, a new hope in non-small cell lung cancer. Bull Cancer. 2015; 102: 1046-1052. Ref.: https://goo.gl/UnmCy2

21. Kazandjian D, Suzman DL, Blumenthal G, Mushti S, He K, et al. FDA Approval Summary: Nivolumab for the Treatment of Metastatic Non-Small Cell Lung Cancer with Progression on or After PlatinumBased Chemotherapy. Oncologist. 2016; 21: 634-642. Ref.: https://goo.gl/ErnYGR

22. Takahama T, Sakai K, Takeda M, Azuma K, Hida T, et al. Detection of the T790M mutation of EGFR in plasma of advanced non-small cell lung cancer patients with acquired resistance to tyrosine kinase inhibitors (West Japan oncology group 8014LTR study). Oncotarget. 2016; 7: 58492-58499. Ref.: https://goo.gl/qdMcK5

23. Holla VR, Elamin YY, Bailey AM, Johnson AM, Litzenburger BC, et al. ALK: a tyrosine kinase target for cancer therapy. Cold Spring Harb Mol Case Stud. 2017; 3: 001115. Ref.: https://goo.gl/w8W2wP

24. Nguyen-Ngoc T, Bouchaab H, Adjei AA, Peters S. BRAF Alterations as Therapeutic Targets in NonSmall-Cell Lung Cancer. J Thorac Oncol. 2015; 10: 1396-403. Ref.: https://goo.gl/2SJBL4

25. Takeda M, Nakagawa K. Role of EGFR Monoclonal Antibodies in the Management of Non-small Cell Lung Cancer. Curr Cancer Drug Targets. 2015; 15: 792-802. Ref.: https://goo.gl/tCiSYs

26. Ostoros G, Dome B. [Erlotinib in the treatment of non-small cell lung cancer]. Magy Onkol. 2006; 50: 237-241. Ref.: https://goo.gl/vdVRUy

27. Cohen MH, Johnson JR, Chattopadhyay S, Tang S, Justice R, et al. Approval summary: erlotinib maintenance therapy of advanced/metastatic non-small cell lung cancer (NSCLC). Oncologist. 2010; 15: 1344-1351. Ref.: https://goo.gl/Ue64Uj

28. Khozin S, Gideon M. Blumenthal, Xiaoping Jiang, Kun He, Karen Boyd, et al. U.S. Food and Drug Administration approval summary: Erlotinib for the first-line treatment of metastatic non-small cell lung cancer with epidermal growth factor receptor exon 19 deletions or exon 21 (L858R) substitution mutations. Oncologist. 2014; 19: 774-779. Ref.: https://goo.gl/gRPh6T

29. Nelson V, Ziehr J, Agulnik M, Johnson M. Afatinib: emerging next-generation tyrosine kinase inhibitor for NSCLC. Onco Targets Ther. 2013; 6: 135-143. Ref.: https://goo.gl/Z5X565

30. Dungo RT, Keating GM. Afatinib: first global approval. Drugs. 2013; 73: 1503-1515. Ref.: https://goo.gl/5iW5ny

31. Campbell $L$, Blackhall $F$, Thatcher N. Gefitinib for the treatment of non-small-cell lung cancer. Expert Opin Pharmacother. 2010; 11: 1343-1357. Ref.: https://goo.gl/JDPmM8

32. No author listed. Gefitinib Approved for EGFR-Mutated NSCLC. Cancer Discov. 2015; 5: 896. Ref.: https://goo.gl/MrygSG

33. McCoach $\mathrm{CE}$, Jimeno A. Osimertinib, a third-generation tyrosine kinase inhibitor targeting nonsmall cell lung cancer with EGFR T790M mutations. Drugs Today (Barc). 2016; 52: 561-568. Ref.: https://goo.gl/oUoXud

34. Greig SL. Osimertinib: First Global Approval. Drugs. 2016; 76: 263-273. Ref.: https://goo.gl/naWk1f

35. Ou SH. Crizotinib: a drug that crystallizes a unique molecular subset of non-small-cell lung cancer. Expert Rev Anticancer Ther. 2012; 12: 151-162. Ref.: https://goo.gl/ojZoKx

36. Shaw AT, Solomon B, Kenudson MM. Crizotinib and testing for ALK. J Natl Compr Canc Netw. 2011; 9: 1335-1341. Ref.: https://goo.gl/qPGzc7

37. Bubendorf L, Büttner R, Al-Dayel F, Dietel M, Elmberger G, et al. Testing for ROS1 in non-smal cell lung cancer: a review with recommendations. Virchows Arch. 2016; 469: 489-503. Ref.: https://goo.gl/uRyTWQ

38. Cooper MR, Chim H, Chan H, Durand C. Ceritinib: a new tyrosine kinase inhibitor for non-small-cell lung cancer. Ann Pharmacother. 2015; 49: 107-112. Ref.: https://goo.gl/xYRmGt

39. Guha M. Novartis' lung cancer ALK inhibitor approved. Nat Biotechnol, 2014; 32: 607. Ref.: https://goo.gl/aP2c6g

40. Avrillon V, Perol M. Alectinib for treatment of ALK-positive non-small-cell lung cancer. Future Oncol. 2017; 13: 321-335. Ref.: https://goo.gl/6A5Gfp 
41. Larkins $\mathrm{E}$, Blumenthal GM, Chen $\mathrm{H}, \mathrm{He} \mathrm{K}$, Agarwal R, et al. FDA Approval: Alectinib for the Treatment of Metastatic, ALK-Positive Non-Small Cell Lung Cancer Following Crizotinib. Clin Cancer Res. 2016; 22: 5171-5176. Ref.: https://goo.gl/2KALyE

42. Siaw JT, Wan H, Pfeifer K, Rivera VM, Guan J, et al. Brigatinib, an anaplastic lymphoma kinase inhibitor, abrogates activity and growth in ALK-positive neuroblastoma cells, Drosophila and mice. Oncotarget. 2016; 7: 29011-29022. Ref.: https://goo.gl/d1cbXg

43. Asati V, Bharti SK, Mahapatra DK. Mutant B-Raf Kinase Inhibitors as Anticancer Agents. Anticancer Agents Med Chem. 2016; 16: 1558-1575. Ref.: https://goo.gl/VdGM8T

44. Smida M, Fece de la Cruz F, Kerzendorfer C, Uras IZ, Mair B, et al. MEK inhibitors block growth of lung tumours with mutations in ataxia-telangiectasia mutated. Nat Commun. 2016; 7: 13701. Ref.: https://goo.gl/oGb69r 